\title{
Estimation and Validation of Land Surface Broadband Albedos and Leaf Area Index From EO-1 ALI Data
}

\author{
Shunlin Liang, Senior Member, IEEE, Hongliang Fang, Monisha Kaul, Tom G. Van Niel, Tim R. McVicar, \\ Jay S. Pearlman, Senior Member, IEEE, Charles L. Walthall, Senior Member, IEEE, Craig S. T. Daughtry, and \\ Karl Fred Huemmrich
}

\begin{abstract}
The Advanced Land Imager (ALI) is a multispectral sensor onboard the National Aeronautics and Space Administration Earth Observing 1 (EO-1) satellite. It has similar spatial resolution to Landsat-7 Enhanced Thematic Mapper Plus (ETM+), with three additional spectral bands. We developed new algorithms for estimating both land surface broadband albedo and leaf area index (LAI) from ALI data. A recently developed atmospheric correction algorithm for ETM+ imagery was extended to retrieve surface spectral reflectance from ALI top-of-atmosphere observations. A feature common to these algorithms is the use of new multispectral information from ALI. The additional blue band of ALI is very useful in our atmospheric correction algorithm, and two additional ALI near-infrared bands are valuable for estimating both broadband albedo and LAI. Ground measurements at Beltsville, MD, and Coleambally, Australia, were used to validate the products generated by these algorithms.
\end{abstract}

Index Terms-Atmospheric correction, Advanced Land Imager (ALI), broadband albedos, Earth Observing 1 (EO-1), leaf area index (LAI), validation.

\section{INTRODUCTION}

$\mathbf{E}$ ARTH Observing 1 (EO-1) is the first satellite of the National Aeronautics and Space Administration (NASA) New Millennium Program Earth Observing series. EO-1 was launched on November 21, 2000. It flies 1 min behind Landsat-7 in the same orbit and carries three sensors: the Advanced Land Imager (ALI), Hyperion, and Atmospheric Corrector (AC). Both Hyperion and $\mathrm{AC}$ are hyperspectral sensors with more than 200 bands. The ALI is a multispectral sensor. These three advanced imaging instruments will lead to

\footnotetext{
Manuscript received August 9, 2002; revised February 19, 2003. This work was supported in part by the National Aeronautics and Space Administration under Grant NCC 5462 and by funding provided by the Australian Federal Government to the Commonwealth Scientific and Industrial Research Organization and the Cooperative Research Centre for Sustainable Rice Production, Project 1105 .

S. Liang and H. Fang are with the Department of Geography, University of Maryland, College Park, MD 20742 USA (e-mail: sliang@geog.umd.edu).

M. Kaul, C. L. Walthall, and C. S. T. Daughtry are with the Hydrology and Remote Sensing Laboratory, U.S. Department of Agriculture, ARS, Beltsville, MD 20705 USA

T. G. Van Niel and T. R. McVicar are with the Commonwealth Scientific and Industrial Research Organization Land and Water, Canberra, ACT 2601, Australia.

J. S. Pearlman is with the Advanced Network Centric Operations, Phantom Works, Boeing Company, Seattle, WA 98124 USA.

K. F. Hummerich is with the Joint Center for Earth Systems Technology, University of Maryland Baltimore County, Catonsville, MD 21250 USA.

Digital Object Identifier 10.1109/TGRS.2003.813203
}

a new generation of lighter weight, higher performance, and lower cost Landsat-type imaging instruments for the NASA Earth Science Enterprise. Additionally, the EO-1 Mission validates a number of cross-cutting spacecraft subsystem technologies that will enable future earth and space science missions to be conducted using smaller, lower weight, and reduced-power spacecraft buses. Studies presented in this special issue have also proven that EO-1 data can be applied to address a variety of earth environment and resource issues. A detailed description of the EO-1 mission is given by Ungar et al. [30].

The spatial resolutions of ALI are very similar to Landsat-7 ETM+. Note the three additional spectral bands of ALI: 0.43-0.45 $\mu \mathrm{m}$ (1p), 0.85-0.89 $\mu \mathrm{m}(4 \mathrm{p})$, and $1.20-1.30 \mu \mathrm{m}$ (5p). The objective of this study is to assess if ALI observations can be used to estimate land surface biophysical variables accurately. To achieve this goal, we developed and tested a series of new algorithms, and validated the derived products using correlative ground measurements.

We have focused on two biophysical variables in this study: broadband albedo and leaf area index (LAI). Broadband albedo is a fundamental component that determines the earth's climate [1]-[3]. It is a parameter needed by both global and regional climate models, and for computing the surface energy balance. The seasonal and long-term vegetation dynamics that significantly impact climate are accompanied by dramatic variations of albedo. Remote sensing is the only practical means for mapping land surface albedo. LAI is an important structural property of vegetation, and is a basic quantity driving many land surface models.

There are two important preprocessing steps when estimating these two biophysical variables quantitatively [4]. The first is sensor radiometric calibration that converts digital numbers (DNs) to a top-of-atmosphere (TOA) radiance. The reader is referred to the EO-1 summary paper by Ungar et al. [30] for details on this process. The second step is atmospheric correction to convert the TOA radiance to surface reflectance. If all atmospheric parameters are known, correcting broadband multispectral instruments for atmospheric affects is straightforward. The difficulty is estimating some of these key variables from the imagery itself. Since most commercial image processing software packages have not been modified for this purpose, we have made substantial efforts to extend our previously published atmospheric correction algorithm for Landsat-7 ETM+ imagery [5], [6]. The details are discussed as Sections II-A and III-A. 
There are two approaches for estimating land surface broadband albedo from multispectral remote sensing observations. The first builds on our understanding of physical processes. It consists of the following:

1) atmospheric correction that converts the TOA radiance to surface directional reflectance;

2) bidirectional reflectance distribution function (BRDF) modeling that converts directional reflectance to narrowband albedos;

3) narrowband-to-broadband spectral conversions (e.g., the Moderate Resolution Imaging Spectroradiometer (MODIS) albedo algorithm [7], [8]).

An advantage of using this approach is that we know where to improve the algorithms as more data are accumulated and as knowledge advances. The disadvantage is that any errors associated with each processing step may be propagated and significantly impact the accuracy of the final broadband albedo product.

The second approach for estimating land surface broadband albedo from multispectral remote sensing observations is a hybrid that combines extensive radiative transfer simulations (physical) with nonparametric regression methods (statistical). It directly links the TOA radiance to surface broadband albedo without performing different processes as per the first approach. This approach has been successfully used to estimate broadband albedo from MODIS data [9].

The first approach has been adapted for this study. A comparison of both approaches is planned for a future study using ALI data.

There has been a long history of estimating canopy LAI from multispectral satellite observations. The typical approaches include statistical regression based on vegetation indixes [10]-[12], optimization inversion [10]-[12], lookup table searching [13], [14], and hybrid inversion algorithms [15]-[17]. In this study, we employ the hybrid inversion method [18]. This approach combines our current understanding of radiation transfer in vegetation canopies and state-of-the-art statistical estimation techniques. The details are discussed as Sections II-C and III-C.

Validation of the products derived from satellite data has been an important part of this study. We conducted field campaigns at both Beltsville Agricultural Research Center (BARC), MD, and Coleambally Irrigation Area Region (CIAR), Australia. Extensive correlative measurements were made, and some ancillary information was also collected. The details will be presented in Section II-D.

\section{MethodS}

A flowchart of methods is shown as Fig. 1. The absolute radiometric calibration generates the coefficients for converting DNs to TOA radiance. Following atmospheric correction to surface spectral reflectance, the retrieved surface reflectances are used to estimate both broadband albedo and LAI. Correlative surface measurements are then used to validate surface reflectance, broadband albedos, and LAI.

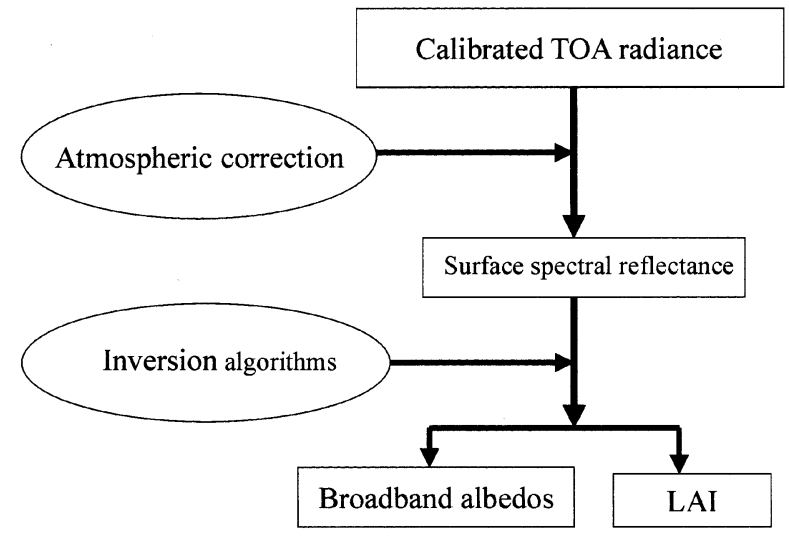

Fig. 1. Flowchart of methods.

\section{A. Atmospheric Correction}

Recently, we developed a new atmospheric correction algorithm to remove the heterogeneous aerosol effects of Landsat-7 ETM+ imagery [5]. The algorithm consists of five steps.

Step 1) Distinguish hazy and clear regions using the visible bands (mostly contaminated by aerosols).

Step 2) Group all pixels into clusters using near infrared (NIR) (these are less contaminated by aerosols).

Step 3) Determine surface reflectance of clear pixels by searching lookup tables created from MODTRAN.

Step 4) Match surface reflectance of hazy pixels with that of clear pixels.

Step 5) Determine the aerosol optical depths of the hazy pixels with a spatial smoothing process.

This procedure has been used successfully to correct many hazy images. The retrieved surface reflectances have compared extremely well with correlative ground measurements [6].

This algorithm was modified to correct ALI imagery by adjusting the lookup tables for the ALI spectral response functions. One of the difficult tasks of this algorithm is distinguishing hazy pixels from clear pixels, especially when the background is very bright. At shorter wavelengths, surface reflectance tends to be lowered because of stronger atmospheric scattering. We have explored several methods for determining hazy regions on ETM+ imagery [5]. The clustering method gave the most satisfactory results for the first few shortwave bands. The extra blue band of ALI has contributed greatly to the success of this approach.

\section{B. Narrowband-to-Broadband Albedo Conversion}

The algorithm we adapted for calculating surface broadband albedo consists of 1) atmospheric correction, 2) angular modeling of surface reflectance, and 3) narrowband-to-broadband albedo conversion. The procedure is illustrated in Fig. 2. The assumption of a Lambertian surface is used for the angular modeling, as there is not enough information available from ALI for an accurate angular model. Thus, the surface reflectance retrieved from the atmospheric correction step is equal to spectral albedos. The final step converts narrowband albedo to broadband albedo. 


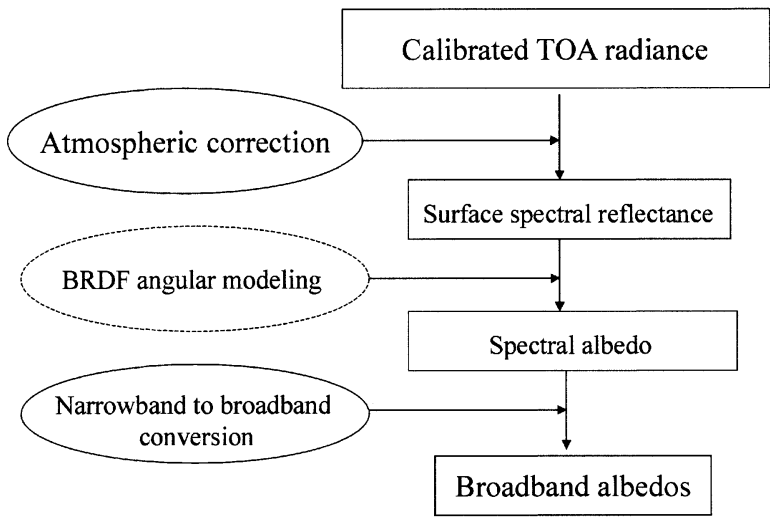

Fig. 2. Procedure for deriving surface broadband albedos. Note in this study BRDF modeling was not performed due to assumptions of a Lambertian surface. This is shown by the dashed line in the flowchart.

Conversion formulas exist in the literature that were developed from limited observations and/or simple radiative transfer simulations. These solutions are mainly for total shortwave broadband albedo. A procedure for determining the conversion coefficients for a variety of sensors based on extensive radiative transfer simulations and linear regression analysis was recently developed [19]. These formulas proved very accurate for predicting broadband albedo based on extensive ground measurements [20]. The same approach was applied here to establish conversion formulas for ALI. The MODTRAN atmospheric optics simulation model was used to simulate broadband albedo for a range of atmospheric conditions and surface reflectance spectra. Linear regression analysis is used to produce the conversion formulas.

Most studies in the literature provide conversion formulas for calculating only the total shortwave broadband albedo. The visible and NIR broadband albedos are quite often needed for land surface modeling. Moreover, both total visible and NIR broadband albedos are further divided into direct and diffuse albedos. Forexample, theNASAGoddardEarthObservation System-Data Assimilation System (GEOS-DAS) surface model [21], National Center for Atmospheric Research (NCAR) community climate model [1], and the simple biospheric model [22], [23] use all four broadband albedos of the visible and NIR region. It is desirable to generate direct and diffuse visible and NIR broadband albedo directly from satellite observations to calibrate and validate these land surface models.

The following are the formulas for converting ALI narrowband albedos to three broadband albedos (visible: $0.4-0.7 \mu \mathrm{m}$; NIR: $0.7-2.5 \mu \mathrm{m}$; total shortwave: $0.35-2.5 \mu \mathrm{m}$ ) based on the same procedure reported earlier [19], [20]:

$$
\begin{aligned}
\alpha_{\text {short }}= & 0.3466 r_{1 \mathrm{p}}-0.1435 r_{1}+0.2278 r_{2}+0.0985 r_{3} \\
& +0.0574 r_{4}+0.2159 r_{4 \mathrm{p}}+0.0385 r_{5}+0.1139 r_{5 \mathrm{p}} \\
& +0.0620 r_{7} \\
\alpha_{\text {vis }}= & 0.2812 r_{1 \mathrm{p}}+0.1248 r_{1}+0.3592 r_{2}+0.2353 r_{3} \\
\alpha_{\text {vis-dif }}= & 0.3824 r_{1 \mathrm{p}}+0.1138 r_{1}+0.3366 r_{2}+0.1681 r_{3} \\
\alpha_{\text {vis-dir }}= & 0.2254 r_{1 \mathrm{p}}+0.1401 r_{1}+0.3707 r_{2}+0.2640 r_{3} \\
\alpha_{\mathrm{NIR}}= & 0.2917 r_{4}+0.2707 r_{4 \mathrm{p}}-0.0316 r_{5}+0.2502 r_{5 \mathrm{p}} \\
& +0.2258 r_{7}
\end{aligned}
$$

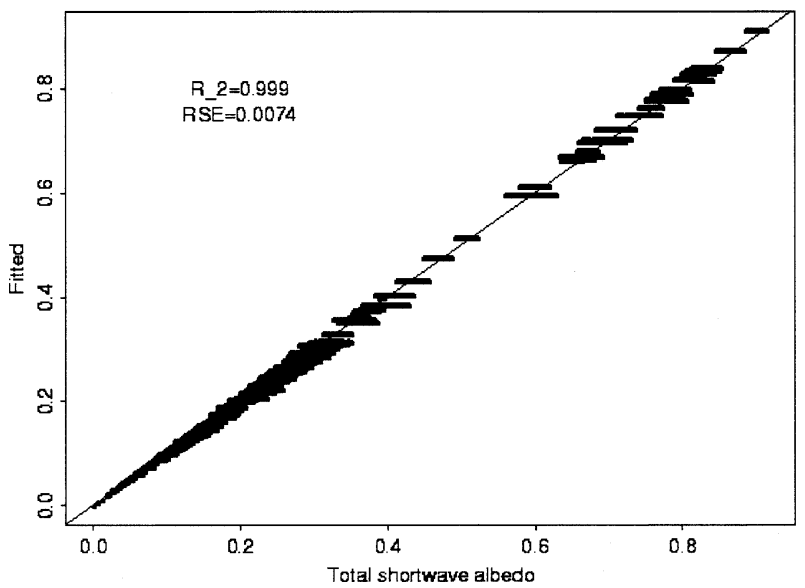

Fig. 3. Fit of the linear conversion formula for the total shortwave.
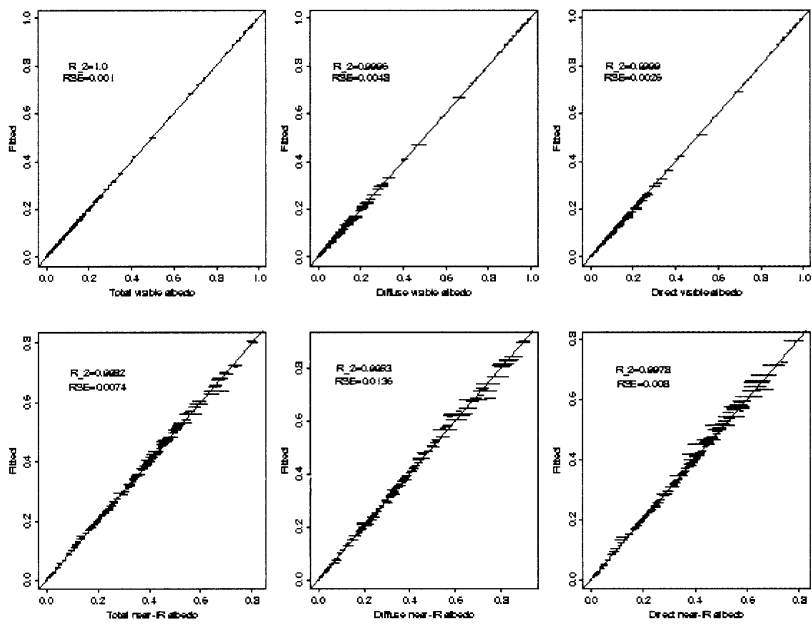

Fig. 4. Fit of the linear conversion formulas for the visible and NIR.

$$
\begin{aligned}
\alpha_{\mathrm{NIR}-d i f}= & 0.5468 r_{4}+0.2012 r_{4 \mathrm{p}}-0.1531 r_{5}+0.1799 r_{5 \mathrm{p}} \\
& +0.2418 r_{7} \\
\alpha_{\mathrm{NIR}-\text { dir }}= & 0.2609 r_{4}+0.2726 r_{4 \mathrm{p}}-0.0104 r_{5}+0.2615 r_{5 \mathrm{p}} \\
& +0.2179 r_{7}
\end{aligned}
$$

where $r_{x}$ is the reflectance of all band $x$; specifically, $r_{1 \mathrm{p}}, r_{4 \mathrm{p}}$, and $r_{5 \mathrm{p}}$ are the reflectance of ALI bands $1 \mathrm{p}, 4 \mathrm{p}$, and 5p, respectively; and dir and dif represent direct and diffuse components. The fitted intercept constants are small and have been omitted for the above formulas. Figs. 3 and 4 demonstrate that these linear functions fit the simulated data very well.

\section{Hybrid Inversion Method for Retrieving LAI}

Statistical and physical algorithms are used to estimate LAI from remote sensing observations. Statistical algorithms rely on spectral vegetation indixes that are linked with calibration LAI measurements. They are simple and easy to implement. Unfortunately, a universal relationship suitable for all species over all regions does not appear to exist. Physical models are based on canopy reflectance model inversions. The traditional optimum inversion schemes are very time consuming and difficult for regional applications. Lookup table and artificial neural network (ANN) approaches have been used to speed up the process. A 


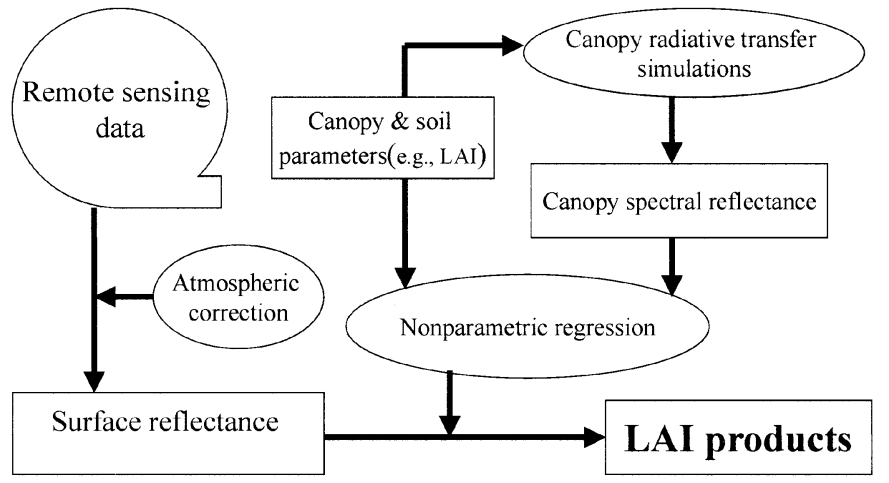

Fig. 5. Hybrid procedure for estimating LAI

new approach, called a hybrid algorithm, combines canopy radiative transfer simulations with statistical regression using an ANN.

Our inversion algorithm is also a hybrid algorithm, similar to the approach for estimating broadband albedo (Fig. 5). The hybrid model is based on an initial off-line signature training [18], which is illustrated in the upper right corner of Fig. 5. These signatures are generated through extensive canopy radiative transfer simulations with variable inputs of different variables. The trained algorithm can be then used for online determination of the LAI values from remotely sensed data.

The physical part of the hybrid algorithm uses a canopy radiative transfer model for extensive simulations. For this study, we used the canopy radiative transfer model developed by Kuusk [24], [25]. The model outputs spectral reflectances that are then integrated into ALI band reflectances using the ALI spectral response functions. The statistical part of the hybrid algorithm uses a nonparametric regression algorithm (i.e., ANN) to link LAI and band reflectance. A major difference from the lookup table approach is that we do not have to fix most input variables (set them as constants) for the hybrid algorithm. During the canopy reflectance model simulations, many variables are used, each with a reasonable range. Then, the nonparametric regression algorithm links band reflectance with only the variables of interest (i.e., LAI in the current case).

Theoretically, we can keep every variable free during the simulation stage. It is, however, desirable to fix certain variables to which the band reflectances are not sensitive as realistic canopy models contain a few dozen variables. The reader is referred to the published algorithm description for details [18].

The Kuusk canopy model is very sensitive to soil reflectance. As it is unrealistic to vary multispectral soil reflectance randomly, the concept of a soil reflectance index based on the soil line concept was used [26]. By examining the red and NIR two-dimensional spectral reflectance space from the ALI imagery, a soil-line index was devised with its minimum value $(0)$ at the low end of the soil line, and the maximum value (1) at the high end of the soil line. A soil-line index value corresponds to a set of multispectral soil reflectance that are interpolated.

Another important issue is to select the most favorable bands for the hybrid algorithm for a particular attribute (e.g., LAI), since certain bands are more sensitive to other factors. Using simulations, we select the best band combinations based on the
TABLE I

Best ALI COMBINATIONS FOR LAI RETRIEVAL. SPECTRAL BANDS Are Designated by Band Number. $p$ Represents Prime. DETAILS CAN BE FOUND IN [30]

\begin{tabular}{|c|c|c|c|c|c|}
\hline Bands & $R^{2}$ & RMSE & Bands & $R^{2}$ & RMSE \\
\hline 23 & 0.830 & 1.231 & $344 p$ & 0.785 & 1.678 \\
\hline 24 & 0.783 & 1.786 & $345 p$ & 0.887 & 1.135 \\
\hline $24 p$ & 0.817 & 1.535 & 345 & 0.735 & 2.087 \\
\hline $25 p$ & 0.720 & 2.202 & $34 p 5 p$ & 0.914 & 0.977 \\
\hline 25 & 0.679 & 2.215 & $34 \mathrm{p} 5$ & 0.732 & 2.078 \\
\hline 34 & 0.800 & 1.671 & $35 p 5$ & 0.721 & 2.133 \\
\hline $34 p$ & 0.821 & 1.516 & $44 p 5 p$ & 0.945 & 0.739 \\
\hline $35 p$ & 0.762 & 1.900 & $44 p 5$ & 0.947 & 0.697 \\
\hline 35 & 0.760 & 1.810 & $45 \mathrm{p} 5$ & 0.947 & 0.705 \\
\hline $44 p$ & 0.966 & 0.535 & $4 p 5 p 5$ & 0.603 & 2.902 \\
\hline $45 p$ & 0.878 & 1.197 & $2344 p$ & 0.823 & 2.902 \\
\hline 45 & 0.846 & 1.365 & $2345 p$ & 0.887 & 1.141 \\
\hline $4 p 5 p$ & 0.951 & 0.682 & 2345 & 0.714 & 2.263 \\
\hline $4 \mathrm{p} 5$ & 0.892 & 1.050 & $234 p 5 p$ & 0.916 & 0.941 \\
\hline $5 \mathrm{p} 5$ & 0.846 & 1.308 & $234 \mathrm{p} 5$ & 0.729 & 2.102 \\
\hline 234 & 0.780 & 1.794 & $235 p 5$ & 0.630 & 2.929 \\
\hline $234 p$ & 0.807 & 1.614 & $244 p 5 p$ & 0.718 & 2.197 \\
\hline $235 p$ & 0.737 & 2.078 & $244 p 5$ & 0.493 & 3.601 \\
\hline 235 & 0.690 & 2.417 & 245 p 5 & 0.793 & 1.783 \\
\hline $244 p$ & 0.484 & 4.076 & $24 p 5 p 5$ & 0.876 & 1.181 \\
\hline $245 p$ & 0.873 & 1.240 & $344 p 5 p$ & 0.882 & 1.141 \\
\hline 245 & 0.700 & 2.571 & $344 p 5$ & 0.873 & 1.182 \\
\hline $24 p 5 p$ & 0.933 & 0.826 & $345 p 5$ & 0.876 & 1.186 \\
\hline $24 \mathrm{p} 5$ & 0.738 & 2.207 & $34 p 5 p 5$ & 0.947 & 0.704 \\
\hline $25 \mathrm{p} 5$ & 0.665 & 2.826 & $44 p 5 p 5$ & 0.726 & 1.679 \\
\hline
\end{tabular}

correlation coefficients and residuals between retrieved LAI and true LAI values (Table I). Note that band combinations with an rmse smaller than 1.0 are bolded. Other combinations produced much worse results and are not shown. It is clear from this analysis that the additional bands of ALI (beyond that of ETM+) are very useful for LAI inversion.

\section{Field Campaigns and Ground Measurements}

Extensive field measurements at BARC and CIAR were conducted to validate the data products. BARC is an EOS land core validation site [27], [28]. BARC has variable land cover types, while CIAR has large homogeneous crop fields. Extensive ground measurements were collected coincident with EO-1 imagery acquisitions. Albedometers were used for broadband albedo measurements; field-portable spectroradiometers were used to measure spectral reflectance $(350-2500 \mathrm{~nm})$; and nondestructive optical methods with LAI2000 were used to measure LAI.

\section{DATA ANALYSIS}

\section{A. Atmospheric Correction}

An assessment of the atmospheric correction algorithm to retrieve surface reflectance accurately was deemed necessary 

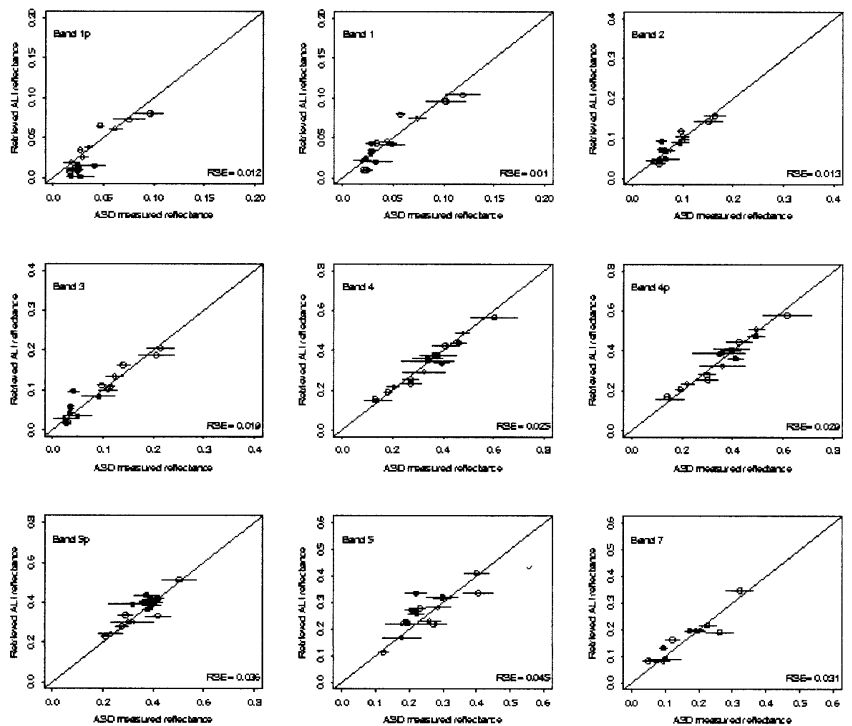

Fig. 6. ALI-derived and measured surface reflectance. The lines represent one standard deviation of the spectroradiometer-measured reflectance. Dates of acquisition were (solid circle, BARC) August 2, 2001, (hollow circle, CIAR) February 3, 2001, and (hollow diamond, CIAR) March 7, 2001.

as a first step. The assessment procedure is nearly identical to that of the ETM+ atmospheric correction algorithm validation [6]. Near the EO-1 overpass time $( \pm 1 \mathrm{~h})$, spectroradiometers were used to measure the reflectance of transects in multiple large, homogeneous plots. The average value of the within-transect samples was used to represent the reflectance of a plot. The average reflectance spectra were then aggregated using the ALI spectral response functions. Fig. 6 shows comparisons of the surface spectral reflectance retrieved from ALI observations with the aggregated surface measurement values. The agreements are generally very good, although not all points match exactly. Factors that may contribute to the differences include selection of an inappropriate aerosol model, and the Lambertian surface assumption, among others. For the first four bands, the residual standard error (RSE) is roughly 0.01 . For most other bands the RSE is close to 0.03 .

An atmospherically corrected image example of suburban Beijing City, China is given in Fig. 7. The color composite imagery shows before (left image) and after (right image) atmospheric correction of three bands $4 \mathrm{p}, 3$, and 2 (red, green, and blue, respectively). Fig. 8 shows the spatial distribution of TOA radiance differences of band 1 . The differences are the original TOA radiance minus the calculated TOA radiance. (The calculated TOA radiance was a forward simulation using the retrieved surface reflectance, a clear atmosphere, and the same solar-viewing geometry.) It is evident that Fig. 8 captures the spatial distribution of the aerosols very well.

\section{B. Broadband Albedo Estimation}

The conversion formulas that were developed from extensive radiative transfer simulations using ground measurements described in Section II-B were first validated. Spectroradiometer and albedometer ground measurements from BARC were utilized from five days: May 11 and August 4, 2000, and February 26, March 1, and March 29, 2001. Data were collected at CIAR

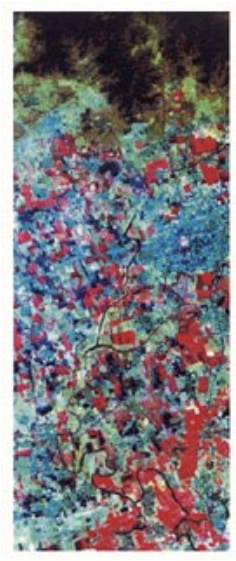

(a)

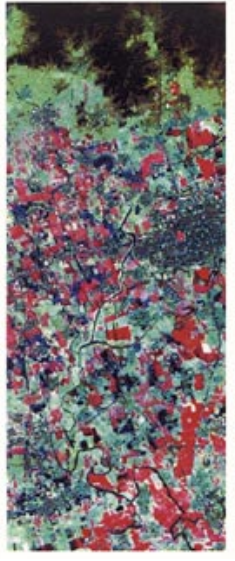

(b)
Fig. 7. False-color composite imagery (a) before and (b) after atmospheric correction (red: $4 \mathrm{p}$, green: 3 , blue: 2 ).

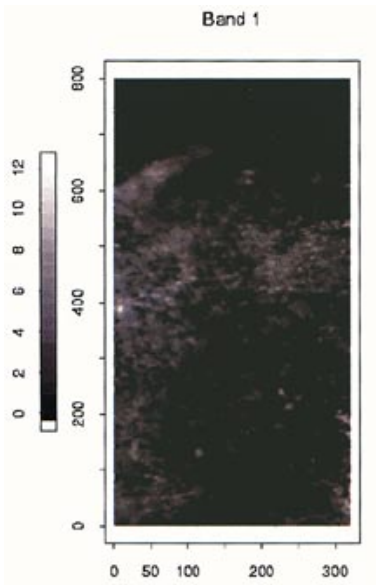

Fig. 8. EO-1 band-1 TOA radiance (in watts per square meter steradian micrometer) difference between before and after atmospheric correction.

on February 3, 2001. Details of the field measurements were presented by Liang et al. [20]. The visible broadband albedo can be deduced from the measured shortwave and NIR up and down radiative fluxes that were measured simultaneously. Fig. 9 compares the measured broadband albedos, with the three broadband albedos calculated using the conversion formulas from Section II-B. The results show excellent agreement. The predictions are not biased, and the residual squared errors for the total shortwave, visible, and NIR albedos are 0.010, 0.016, and 0.022 , respectively.

Following the flowchart of Fig. 2, we can easily generate the broadband albedo maps if the surface is assumed to be Lambertian. Fig. 10 illustrates the retrieved three broadband albedo maps. Visually the spatial patterns and magnitudes look very reasonable.

The assumption of a Lambertian surface was debated when we published similar albedo maps from ETM+ data [20], [29]. The key argument was that the broadband albedo depends on both spectral and angular properties of the land surface. From the validation analysis of this study, and studies for other sensors [20], it appears that an assumption of spectral information dominance over the angular information does not lead to significant errors. 

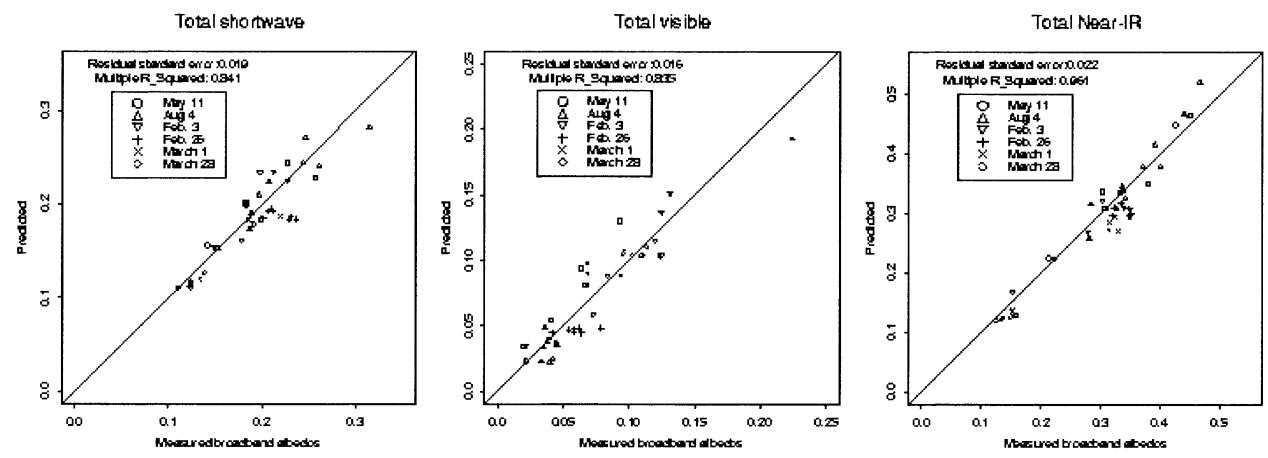

Fig. 9. Validation of the narrowband-to-broadband albedo conversion formulas using correlative ground measurements.
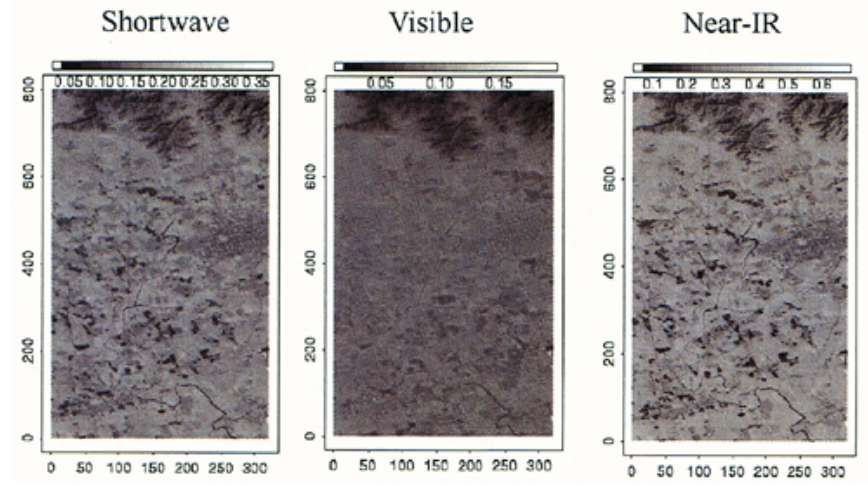

Fig. 10. Broadband albedo maps over Beijing from data shown in Fig. 7.

\section{LAI Estimation}

As in Sections III-A and III-B, the first step is to validate the hybrid inversion algorithm for retrieving LAI from ALI imagery. Field measurements were conducted at both USDA/BARC and CIAR, primarily on three dates with EO-1 overpass: August 2, 2001 at BARC, and February 3, 2001 and January 12, 2002 at CIAR. Our focus is on the agricultural crops.

For each field campaign, we selected multiple small plots within large crop fields. Within each plot, several transects were identified, and LAI measurements were made along each transect using nondestructive methods. Because of geolocation and registration uncertainties, it is difficult to make direct comparisons on the pixel basis. Instead, the average LAI for each field was calculated. Comparisons between the measured and the retrieved LAI are shown in Fig. 11. This illustrates that the inversion algorithm works extremely well. The rmse is only 0.44 . It is important to point out that none of the points in the figure were used to train the model. Additionally, we did not use any ground measurements to tune our algorithm. The ANN was trained using the simulation results from the Kuusk canopy radiative transfer model.

Given the promising performance of the hybrid inversion algorithm, we made LAI maps of our test sites. Fig. 12 shows crop LAI at three different times during the growing season at CIAR using bands 4 and $4 \mathrm{p}$. The temporal patterns make sense for the southern hemisphere summer growing season. Note that the January imagery is from 2002 and is assumed not significantly different from 2001. LAI is highest during January for rice and

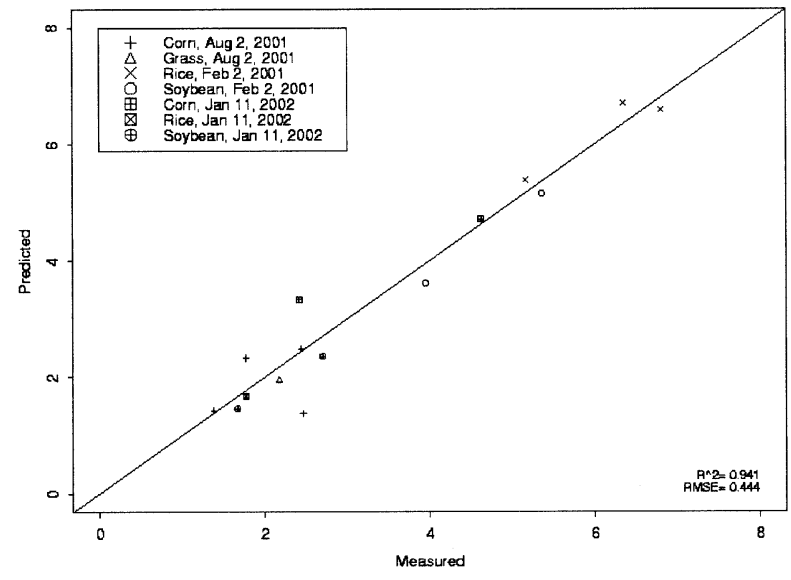

Fig. 11. Comparisons of the retrieved LAI values with the measured LAI values over both BARC and CIAR.

(A)

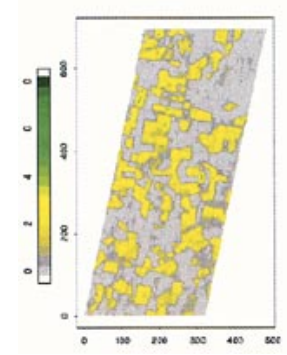

(B)

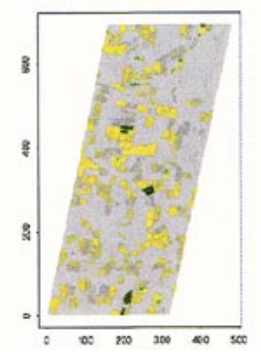

(C)

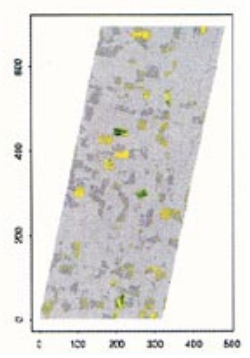

Fig. 12. LAI maps over CIAR from three ALI images. (A) January 12, 2002, (B) February 3, 2001, and (C) March 7, 2001.

corn, and smallest during March, whereas LAI is maximum for soybeans and sorghum during early February.

\section{CONCLUSION}

A series of new algorithms for estimating albedo and LAI using ALI data have been developed and validated through extensive ground measurements at two validation sites. The results indicate that these algorithms are very accurate and that the additional ALI bands beyond those of ETM+ are helpful for atmospheric correction and retrieval of land surface variables.

Since almost all inversion algorithms are based on surface reflectance, atmospheric correction is a necessary step for converting TOA radiance to surface reflectance. It was shown that a newly developed ETM+ atmospheric correction algorithm can 
be successfully extended to correct ALI imagery. The atmospheric correction algorithm can retrieve surface reflectance accurately with small residual errors for shortwave and NIR bands. The algorithm is particularly able to remove the effects of heterogeneous aerosol scattering.

Spectral albedo was approximated as a function of retrieved nadir ALI reflectance. Thus, a Lambertain surface assumption in the atmospheric correction algorithm appears adequate at least for the landscape with the dominate agricultural fields. This supports previous investigations suggesting that wavelength dependence is more important when calculating surface broadband albedo than angular reflectance dependence. New formulas for converting ALI narrowband albedos to broadband albedos appeared to work well, based on comparisons with field measurements made at BARC and CIAR.

A hybrid LAI estimation algorithm that combines extensive canopy radiative transfer simulations (physical) with nonparametric regression methods (statistical) offers a promising alternative to traditional approaches. The algorithm incorporates a soil reflectance index based on the soil line concept. LAI maps for CIAR during the 2000/2001 and 2001/2002 summer growing seasons produced with the hybrid algorithm were sensitive enough to capture expected temporal patterns related to local management and crop phenology.

Future efforts will include incorporation of realistic surface directional reflectance properties into the algorithms. Another will be to extend these algorithms to hyperspectral data, such as Hyperion imagery. Validation of algorithms under different conditions as conducted with this presentation will be integral to the analyses. The comparison will also be performed for ETM and ALI for albedo and LAI. ETM is the baseline and both ALI and Hyperion need to be compared to the current baseline of ETM.

\section{ACKNOWLEDGMENT}

The authors are very grateful to many individuals who helped collect the correlative ground measurements, particularly C. Shuey (University of Maryland) and A. Russ (USDA/BARC). Thanks to D. Jupp [CSRIO Earth Observation Centre (EOC)] for his guidance and assistance in many aspects, to B. Datt and S. Campbell (CSIRO EOC), who assisted with field data collection at CIAR, and L. Thorp for helping process some of these data. The authors would like to thank S. Ungar, for his leadership in the EO-1 project, and to all other EO-1 project staff for their great assistance. Thanks also to landholders who allowed us access to their properties.

\section{REFERENCES}

[1] J. T. Kiehl, J. J. Hack, G. B. Bonan, B. A. Boville, P. Briegleb, D. L. Williamson, and P. J. Rasch, "Description of the NCAR community climate model," National Center for Atmospheric Res., Boulder, CO, NCAR Tech. Note NCAR/TN-420+STR, 1996.

[2] R. E. Dickinson, "Land surface processes and climate-surface albedos and energy balance," Adv. Geophys., vol. 25, pp. 305-353, 1983.

[3] R. D. Cess, "Biosphere-albedo feedback and climate modeling," $J$. Atmos. Sci., vol. 35, pp. 1765-1768, 1978.

[4] S. Liang, Quantitative Remote Sensing of Land Surfaces. New York: Wiley, 2003.

[5] S. Liang, H. Fang, and M. Chen, "Atmospheric correction of landsat ETM+ land surface imagery: I. Methods," IEEE Trans. Geosci. Remote Sensing, vol. 39, pp. 2490-2498, Nov. 2001.
[6] S. Liang, H. Fang, M. Chen, C. Shuey, C. Walthall, and C. Daughtry, "Atmospheric correction of landsat ETM+ land surface imagery: II. Validation and applications," IEEE Trans. Geosci. Remote Sensing, vol. 40, pp. 2736-2746, Dec. 2002.

[7] W. Lucht, C. B. Schaaf, and A. H. Strahler, "An algorithm for the retrieval of albedo from space using semiempirical BRDF models," IEEE Trans. Geosci. Remote Sensing, vol. 38, pp. 977-998, Mar. 2000.

[8] C. Schaaf, A. Strahler, W. Lucht, T. Tsung, F. Gao, X. Li, N. Strugll, L. Chen, P. Muller, P. Lewis, M. Barnsley, P. Hobson, M. Disney, M. Dunderdale, R. d'Entremont, B. Hu, S. Liang, and J. J. Privette, "First operational BRDF, albedo Nadir reflectance products from MODIS," Remote Sens. Environ., vol. 83, pp. 135-148, 2002.

[9] S. Liang, "A direct algorithm for estimating land surface broadband albedos from MODIS imagery," IEEE Trans. Geosci. Remote Sensing, vol. 41, pp. 136-145, Jan. 2003.

[10] C. O. Justice, "Monitoring East African vegetation using AVHRR data," Int. J. Remote Sens., vol. 6, pp. 1335-1372, 1986.

[11] T. N. Carlson and D. A. Ripley, "On the relation between NDVI, fractional vegetation cover, and leaf area index," Remote Sens. Environ., vol. 62, pp. 241-252, 1998.

[12] F. B. Guyot, "Potential and limits of vegetation indices for LAI and APAR assessment," Remote Sens. Environ., vol. 35, pp. 161-173, 1991.

[13] Y. Knyazikhin, J. V. Martonchik, R. B. Myneni, D. J. Diner, and S. W. Running, "Synergistic algorithm for estimating vegetation canopy leaf area index and fraction of absorbed photosynthetically active radiation from MODIS and MISR data," J. Geophys. Res., vol. 103, pp. 32 257-32 275, 1998

[14] Y. Knyazikhin, J. V. Martonchik, D. J. Diner, R. B. Myneni, M. M. Verstraete, B. Pinty, and N. Gobron, "Estimation of vegetation canopy leaf area index and fraction of absorbed photosynthetically active radiation from atmosphere-corrected MISR data," J. Geophys. Res., vol. 103, pp. 32 239-32 256, 1998.

[15] P. Gong, S. X. Wang, and S. Liang, "Inverting a canopy reflectance model using a neural network," Int. J. Remote Sens., vol. 20, pp. 111-122, 1999.

[16] M. Weiss, F. Baret, M. Leroy, O. Hautecoeur, L. Prevot, and N. Bruguier, "Validation of neural net techniques to estimate canopy biophysical variables from remote sensing data," Agronomie, vol. 22, pp. 547-553, 2002.

[17] D. Kimes, J. Gastellu-Etchegorry, and P. Estève, "Recovery of forest canopy characteristics through inversion of a complex 3D model," $R e$ mote Sens. Environ., vol. 79, pp. 320-328, 2002.

[18] H. Fang and S. Liang, "Retrieve LAI from Landsat-7 ETM+ data with a neural network method: Simulation and validation," IEEE Trans. Geosci. Remote Sensing, to be published.

[19] S. Liang, "Narrowband to broadband conversions of land surface albedo," Remote Sens. Environ., vol. 76, pp. 213-238, 2001.

[20] S. Liang, C. Shuey, H. Fang, A. Russ, M. Chen, C. Walthall, C. Daughtry, and R. Hunt, "Narrowband to broadband conversions of land surface albedo: II. Validation,” Remote Sens. Environ., vol. 84, pp. 25-41, 2003.

[21] R. Koster and M. Suarez, "Modeling the land surface boundary in climate models as a composite of independent vegetation stands," J. Geophys. Res., vol. 97, pp. 2697-2715, 1992.

[22] Y. Xue, P. Sellers, J. Kinter III, and J. Shukla, "A simplified biosphere model for global climate studies," J. Climate, vol. 4, pp. 345-364, 1991.

[23] P. J. Sellers, S. O. Los, C. J. Tucker, C. O. Justice, D. A. Dazlich, G. J. Collatz, and D. A. Randall, "A revised land surface parameterization (SiB2) for atmospheric GCM's. Part II: The generation of global fields of terrestrial biophysical parameters from satellite data," J. Climate, vol. 9, pp. 706-737, 1996.

[24] A. Kuusk, "A fast invertible canopy reflectance model," Remote Sens. Environ., vol. 51, pp. 342-350, 1995.

[25] — , "A Markov chain model of canopy reflectance," Agricultur. Forest Meteorol., vol. 76, pp. 221-236, 1995.

[26] F. Baret, S. Jacquemoud, and J. F. Hanocq, "The soil line concept in remote sensing," Remote Sensing. Rev., vol. 7, pp. 65-82, 1993.

[27] C. Justice, D. Starr, D. Wickland, J. Privette, and T. Suttles, "EOS land validation coordination: An update," Earth Obs., vol. 10, pp. 55-60, 1998.

[28] J. Morisette, J. Privette, C. Justice, D. Olson, J. Dwyer, P. Davis, D. Starr, and D. Wickland, "The EOS land validation core sites: Background information and current status," Earth Obs., vol. 11, pp. 11-26, 1999.

[29] S. Liang, F. Fang, M. Chen, C. Shuey, C. Walthall, C. Daughtry, J. Morisette, C. Schaaf, and A. Strahler, "Validating MODIS land surface reflectance and albedo products: Methods and preliminary results," Remote Sens. Environ., vol. 83, pp. 149-162, 2002.

[30] S. Ungar et al., "Overview of the Earth Observing 1 (EO-1) mission," IEEE Trans. Geosci. Remote Sensing, vol. 41, pp. 1149-1159, June 2003 


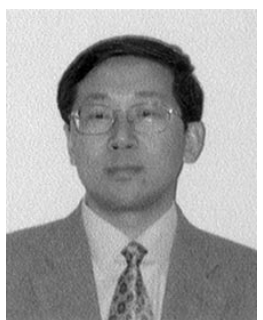

Shunlin Liang (M'94-SM'00) received the Ph.D. degree in remote sensing and GIS from Boston University, Boston, MA.

He was a Postdoctoral Research Associate at Boston University from 1992 to 1993, and Validation Scientist of the NOAA/NASA Pathfinder AVHRR Land Project from 1993 to 1994 . He is currently an Associate Professor at the University of Maryland, College Park. His present research interests focus on land surface data assimilation, parameter retrieval from remotely sensed data, and spatial analysis.

Dr. Liang organized the International Forum on BRDF at San Francisco, CA, in December 1998, and coedited a special issue of the Remote Sensing Reviews. He has chaired various sessions of the international conferences and served as the chairman of the IEEE Geosciences and Remote Sensing Society, Washington/North Virginia Chapter (2000). He is an Associate Editor of the IEEE TRANSACTIONS ON GEOSCIENCE AND REMOTE SENSING.

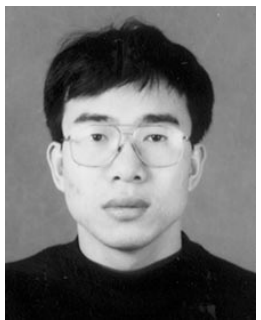

Hongliang Fang received the B.S. degree in geography from East China Normal University, Shanghai, China, in 1993, and the M.S. degree in cartography and GIS from the Institute of Geography, Chinese Academy of Sciences, Beijing, China, in 1996 . He is currently pursuing the Ph.D. degree at the University of Maryland, College Park.

His previous interest was on use of remote sensing and GIS in a variety of fields such as environmen monitoring, land cover/use, biomass monitoring, and wetland ecology. His most recent interest is in retrieving land surface parameters from remotely sensed data.

Monisha Kaul received the B.S. degree in agronomy and the M.S. degree in natural resource sciences from the University of Maryland, College Park, in 1995 and 2001, respectively.

She is currently a Soil Scientist with the Hydrology and Remote Sensing Laboratory (HRSL), U.S. Department of Agriculture's Agricultural Research Service, Beltsville, MD, where she has been a Support Scientist since 2001. Previously, she was with the Laboratory for Global Remote Sensing Studies, Geography Department, University of Maryland, and was based at HRSL as a Faculty Research Assistant.

Tom G. Van Niel received the A.A.S. degree from Monroe Community College, Rochester, NY, and the B.S. and M.S. degrees from Utah State University, Logan.

$\mathrm{He}$ is currently an Experimental Scientist with the Integrated Catchment Management Research Directorate, Commonwealth Scientific and Industrial Research Organization Land and Water, Canberra, Australia and is involved in the Measurement and Mapping Program for the Cooperative Research Centre for Sustainable Rice Production, Yanco, Australia. His research interests are in spatio-temporal analysis as well as error and uncertainty of spatial data.
Tim R. McVicar received the B.S. (honors I) from the University of Queensland, Brisbane, Australia, and the Ph.D. degree from the Australian National University, Canberra, Australia, in 1988 and 2001, respectively.

In 1989, he joined the Division of Water Resources, Commonwealth Scientific and Industrial Research Organization (CSIRO) Land and Water, Canberra, Australia. He is currently a Senior Research Scientist in the Integrated Catchment Management Research Directorate with CSIRO Land and Water, and is a Co-Investigator for the Australian team of the National Aeronautics and Space Administration's EO-1 Science Validation Team. His research interests include time series remote sensing for ecohydrological and agricultural applications

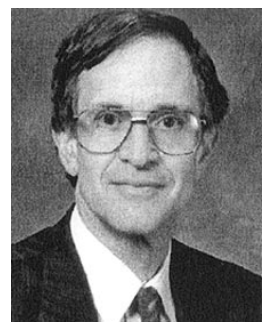

Jay S. Pearlman (M'84-SM'03) received the B.S. degree from the the California Institute of Technology, Pasadena, and the Ph.D. degree from University of Washington, Seattle.

$\mathrm{He}$ is currently the Chief of Science and Applications for the Advanced Network Centric Operations, Phantom Works, Boeing Company, Seattle, WA, and is actively involved in remote sensing development and applications. Previously, he was with TRW, Redondo Beach, CA, and was Deputy Program Manager and Scientist for the Hyperion instrument on EO-1. In addition to instrument development, his activities include applications of remote sensing to agriculture and forestry using both airborne and space-based systems.

Dr. Pearlman is an Associate Editor of the IEEE TRANSACTIONS ON GEOSCIENCE AND REMOTE SENSING.

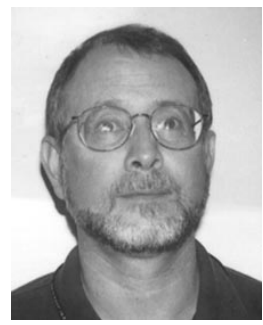

Charles L. Walthall (SM'00) received the B.S. degree in geography from the University of Maryland, College Park, in 1977, the M.S. degree in forest science with a specialization in remote sensing from Texas A\&M, Austin, in 1982, and the Ph.D. degree in agricultural meteorology and climatology/agronomy with a specialization in remote sensing from the University of Nebraska, Lincoln, in 1988.

$\mathrm{He}$ is currently a Physical Scientist with the Hydrology and Remote Sensing Laboratory, U.S. Department of Agriculture's Agricultural Research Service, Beltsville, MD, where he conducts research on remote sensing application to agriculture and natural resources. He has been involved with laboratory, field, airborne, and satellite remote sensing research since 1976. His research interests include remote sensing of vegetation and soils parameters, BRDF, and airborne remote sensing.

Craig S. T. Daughtry, photograph and biography not available at the time of publication.

Karl Fred Huemmrich received the B.S. degree in physics from CarnegieMellon University, Pittsburgh, PA, and the Ph.D. degree in geography from the University of Maryland, College Park.

$\mathrm{He}$ is currently with the Joint Center for Earth Systems Technology, University of Maryland Baltimore County, Catonsville. His work involves determining biophysical variables using remote sensing, combining both models and field measurements. He has worked on a number of field studies including the First International Satellite Land Surface Climatology Project Field Experiment (FIFE) and Boreal Ecosystem and Atmosphere Study (BOREAS). 